\title{
Education and Training in the Field of Machines and Mechanisms (A Comparative Study)
}

\author{
Ibrahim Abdulaziz Al-Darrab and Syed Wasiul Hasan \\ Industrial Engineering Department, Faculty of Engineering, King \\ Abdulaziz University, P.O. Box 80204, Jeddah, 21589, Saudi Arabia \\ iadarab@gmail.com,wasiulhasan@yahoo.com
}

\begin{abstract}
Machines and mechanisms have always been used as tools to improve both the lives and lifestyles of mankind. Human beings started using them by converting natural resources into various forms and shapes of ancient man-made tools. Similar has been the case with one of the most basic areas of mechanical engineering: machines and mechanisms, a field in which human species' invention of the wheel emerged as the foremost and basic entity. As the engineering world progresses the upcoming engineers have to be educated and trained for these latest technological developments and also have to be imparted with more skills in the form of research and development (R\&D) capability. This paper gives an overview of the educational status and training facilities in the field of 'machines and mechanism' in a developing country like Saudi Arabia. The study has revealed that the Kingdom is presently focusing on such areas as mechanics, kinematics, machine design, machine dynamics and theory of machines which are mostly taught in the universities across the Kingdom. The educational and training status of universities in Saudi Arabia compared with those of educationally developed countries like USA in the field of 'machines and mechanism' is discussed. The study revealed that the nature of laboratory based training work, the coverage of the related areas and the methods of teaching these highly technical courses in Saudi universities need to be further improved in order to become comparable to their counterparts in the world. Recently, the Kingdom has initiated work in the field of "nano technology'. What would be its impact on the design and development of future curricula pertaining to machines and mechanisms is highlighted. The paper concludes with certain recommendations that can help policy planners in the field of engineering education, in general, and machines and mechanisms, in particular for the
\end{abstract}


successful future of developing nations to keep pace with the latest innovations.

Keywords: mechanical engineering, university education, curricula, machines, mechanisms, technologies.

\section{Introduction}

Right from the very beginning, the human race has tried innovations to make things under its control and to make life easier for the upcoming generations. Starting from those ancient days of human civilization, discoverers and inventors constantly looked forward, whether it is the design of a simple toy car or a complex aircraft and spaceship system. In such a scenario, the role of academicians in the context of education, research and training has always been most critical and tedious. It started from the ancient period by the invention of wheel and it has reached the latest flying cars made by a students' group of the Massachusetts Institute of Technology (MIT) named "Terrafugia". Thus, our human civilization always remains dependent on engineers and various engineering gadgets for the fulfillment of its needs in every instant of its life. Development of machines, be it the lathe of the industrial revolution or the present day nano-machines, all have been very important in the overall development of humans. Ray Kurzweil, one of 18 thinkers chosen by the US National Academy of Engineering to identify the great technological challenges facing humanity in the $21^{\text {st }}$ century, is quoted saying that "Humanity is on the brink of advances that will see tiny robots implanted in people's brains to make them more intelligent" ${ }^{[1]}$.

The engineer believes that machines and humans will eventually merge through devices implanted in the body to boost intelligence and health. So, in the near future we'll have intelligent nanobots go into our brains to make us smarter. It has already been reported that efforts are being made to develop anthropomorphic robot hands, an endeavor to imitate physiologically the human-hand to be employed in future robots ${ }^{[2-4]}$. Such versatile and ubiquitous is the world of machines and therefore mechanisms which make a machine work in the requisite framework. But for all of these technological advancements, the pre-requisite is the higher education, which actually leads us to the path of progress in this complex scientific world. In the purview of the present paper, it is important to know the role of machines and mechanisms in education and 
thus the development of human civilization, especially in developing countries like Saudi Arabia.

It is important to note that almost all selected universities in the USA, Canada and Saudi Arabia have high international ranking. This makes the comparison more meaningful. The status of education and training in the selected universities can then be assessed by comparing the offering of courses to get a general overview of the situation in these countries. Of course, a deeper study can be undertaken to include many other aspects and factors such as credit hours, teacher/student ratio, level of equipment volume in laboratories, level of strength of the faculty, etc. Since training is done primarily in laboratories, class projects, and senior projects, it is assumed here that all these training activities are undertaken to very high and comparable standards. Of course a deeper investigation might reveal different results. Another important aspect of the comparison, which is not considered in this study, is the output of the educational process at the time of graduation or a few years later. Such factors might also be related to existing opportunities to graduates from these universities. This should lead to a more comprehensive comparative study which goes beyond this general overview.

The next section deals with specifying various aspects of the field of machines and mechanisms, and how it is important for engineering applications.

\section{Machines and Mechanisms}

Mechanical Engineering is one of the oldest and broadest engineering disciplines. This field of engineering applies the principles of physics and materials science for analysis, design, manufacturing, and maintenance of mechanical systems. It is the branch of engineering that involves the production and usage of heat and mechanical power for the design, production, and operation of machines and tools ${ }^{[5]}$. The different sub areas of mechanical engineering discipline can be statics and dynamics; strength of materials and solid mechanics; instrumentation and measurement; thermodynamics, heat transfer, energy conversion and HVAC (heating, ventilation, and air conditioning); fluid mechanics and fluid dynamics; mechanism design (including kinematics and dynamics); manufacturing technology or processes; hydraulics or pneumatics; engineering design; mechatronics and control theory; material 
engineering; drafting, CAD (Computer Aided Design), CAM (Computer Aided Manufacturing) and CIM (Computer Integrated Manufacturing); and many more. Of all the branches listed above, one of the most important branches is that of mechanism.

A mechanism is a combination of resistant bodies, so interconnected that by applying force or motion to one or more of those bodies, some of those bodies are caused to perform desired work accompanied by desired motions ${ }^{[6]}$. The connections present in a mechanism are called kinematic pairs. Kinematic pairs can be classified as higher pair or lower pair. Sometimes an entire machine may be referred to as a mechanism. Examples include the steering mechanism in a car, or the winding mechanism of a wristwatch. When one of the links of a kinematic chain is fixed, the chain is known as a mechanism. Mechanisms are used to convert one type of motion into another. Multiple mechanisms are machines.

The role of machines and mechanisms in engineering world has always been of utmost importance ever since the inception of basic machines in the pre-industrial revolution days. Between the 1860s and 1960s there was an extraordinary quantum leap in humanity's capacity to transform raw metal into very sophisticated machines. Together with contemporary developments in chemistry and electrical and electronics technology, this revolution in metalworking formed the industrial backbone of the modern world ${ }^{[7]}$. Whether it is air travel or satellite based communication, links and mechanisms form an essential part of all the gadgets associated with these technologies. In the present paper, the emphasis is on machines and mechanisms because they are the ubiquitous tools of modern manufacturing and right up to 1980s, they occupied an iconic position in debates about industrial modernization.

In the late nineteenth century, producing pedal-operated sewing machines and bicycles was considered something like a challenge. In the 1940s, things changed so much that the industrialized nations produced high performance aero-engines and combat aircrafts in thousands. All space agencies starting from the American NASA (National Aeronautics and Space Administration) to ISRO (Indian Space Research Organization) have been producing complex mechanisms and linkages for the cryogenic engines, space stations or satellites for that matter. It is evident thus, from this discussion, that machines and mechanisms form 
the basic part of any engineering process, and it is not restricted only to mechanical engineering applications but in all other engineering fields as well. The next section of the paper discusses education and training in this ever growing universal field of machines and mechanisms in general.

\section{Education and Training in the field of Machines \& Mechanisms}

Importance of education has always been there ever since the humans realized the importance of knowledge in their lives. The overall goal of engineering education is to prepare students to practice engineering and, in particular, to deal with the forces and materials of nature ${ }^{[8]}$. And so is the case of acquiring higher education to cross the barriers of ignorance and move towards creative innovations. If these innovations are technological in nature, then the importance of higher education can never be ignored, and that too in the world where the curve for the rate of obsolescence is increasingly steep. For a country to achieve big milestones in the newest technologies, it is very important for its institutions to impart high quality higher education to its citizens.

In the engineering context, the higher education is mainly imparted through high quality labs that may contain top-notch latest gadgets, to let the students understand the technologies in a practical manner. The importance of high quality laboratories can be realized more in the case of the lesser industrialized nations like Saudi Arabia. From the earliest days of engineering education, instructional laboratories have been an essential part of undergraduate and, in some cases, graduate programs. As an example, it is interesting to note that the first engineering school in the United States, the U.S. Military Academy, founded at West Point, New York, in 1802 to produce and train military engineers ${ }^{[9]}$, was based in part on the French curricular model of mathematical rigor, and was also coupled with practice, striking a balance of sorts between theory and practice. For laboratory courses, engineering faculty are much more likely to identify course goals than they are to specify student learning objectives.

A common goal is to relate theory and practice or to bring the "real world" into an otherwise theoretical education. Another goal is to provide motivation either to continue in the study of engineering or to follow a particular course of study. The American Accreditation Board for 
Engineering and Technology (ABET) also gives enough emphasis to lab work and students' performance in some courses gets enough weight just on the practical part of the course. The laboratory work in the fields of machines and mechanisms is also of utmost importance because of its significance in the mechanical engineering arena. Some of the modern tools of teaching and training in this particular area, and for other engineering areas for that matter, include but are not limited to overhead projectors, laptop computers, and calculators. Newer tools such as "smartphones" and games (both online and offline) are beginning to draw serious attention for their learning potential ${ }^{[10]}$.

Although some of these tools are already in use by teaching institutions all over the world, many of the newer technologies need to be implemented to make sure that students properly receive instructional classes they are attending in traditional type of learning. In developing countries, specifically Saudi Arabia, the engineering institutions are using teaching tools such as Liquid Crystal Display (LCD) projectors with wireless access, net uploads of teaching materials etc. and modern lab facilities as well. What more can be done in this respect is to employ tools like class web blogs, clickers and smart phones to share the students' problems and suggestions, discuss assignment questions etc.

The next section deals with the global vis-à-vis Saudi Arabian scenarios considering the type of courses being taught, and their practical part, through labs, specifically in the area of machines and mechanisms.

\section{The Global Scenario}

In general, mechanical engineering is the greenest of all the areas of engineering. Within that, the areas related to machines and mechanisms are numerous. The courses taught in this area of mechanical engineering are mostly the same in almost all the universities throughout the world. In the Western world, courses such as statics and within that statics of deformable solids is common along with a few courses like kinematics and dynamics, and intermediate dynamics of machines, as is taught in US universities like Carnegie Mellon University. Some more courses such as robotics and micro/nano robotics are also included in this category. Almost all major universities of US and Canada are considered here which are listed in the table of comparisons. 
This study considers three countries, USA, Canada and Saudi Arabia. The sample of American universities consists of 20 universities primarily from the top 500 universities. The Canadian sample consists of 17 universities which have high international ranking. For example, the University of Saskatchewan's College of Engineering and the Mechanical Engineering programs are ranked in the top 20 schools in North America. The Canadian Engineering Accreditation Board has accredited the Department of Mechanical Engineering since the beginning of the program in $1965^{[11]}$. Since Saudi Arabia has a small number of universities, the KSA sample consists of 7 prominent universities. Remaining universities or colleges are either under construction or have recently been established.

The methodology is to study the courses, taught in each university at the undergraduate level, related to machines and mechanisms as per the topic of the paper. The different topics listed are categorized in similar types of areas as is there in the case of the area "Mechanisms (Analysis and Design)" where in, both, the Analysis and the Design aspects relating to different types of mechanisms are considered. Ten areas are considered to come in the purview of the present paper. Table 1 shows nine areas that appear in US universities as indicated by their websites ${ }^{[11]}$.

Table 1. Universities in US offering courses covering topics of machines and mechanisms.

\begin{tabular}{|l|l|}
\hline Courses & Universities in USA \\
\hline Combustion Engines & $1,4,16,17,18,20$ \\
\hline Kinematics of Machines/Mechanisms & $1,2,5,7,8,11,12,15,20$ \\
\hline Mechanisms (Analysis and Design) & $2,10,12,13,14,15,17,18$ \\
\hline Dynamics of Machines/Components & $1,2,3,4,6,7,8,9,10,11,12,13,14,15,16,17,18,19,20$ \\
\hline Robotics & $1,4,8,9,16,20$ \\
\hline Manufacturing Processes/Machines & $3,4,5,7,11,12,13,14,15,16$ \\
\hline Nanomachines & $2,4,20$ \\
\hline Static Machines & $1,9,12,15$ \\
\hline Motors and Turbomachinery & $5,17,20$ \\
\hline
\end{tabular}

Note: Universities are given numbers as are listed in Appendix A.

Similarly, the sample of main universities of Canada is considered and the results are shown in Table 2. In case of Canadian universities, an additional course named "Fluid Machinery" is being included, which is being offered in Carleton University and University of Ottawa. This course covers the types of fluid machinery, including details of machines such as pumps, compressors and turbines. Finally, in developing 
countries, the KSA model is chosen where the sample of seven universities is evaluated. The results are given in Table 3.

Table 2. Universities in Canada offering courses covering topics of machines and mechanisms.

\begin{tabular}{|l|l|}
\hline Courses & Universities in Canada \\
\hline Combustion Engines & $1,2,5,15,17$ \\
\hline Kinematics of Machines/Mechanisms & $2,7,8,10,12,13,15,17$ \\
\hline Mechanisms (Analysis and Design) & $1,3,4,5,6,7,8,9,10,11,12,14,15,17$ \\
\hline Dynamics of Machines/Components & $1,2,4,5,6,7,8,9,10,11,12,13,14,15,16,17$ \\
\hline Robotics & $1,2,3,5,9,13,14,15$ \\
\hline Manufacturing Processes/Machines & $4,6,7,8,9,10,13,15$ \\
\hline Nanomachines & None \\
\hline Static Machines & 4 \\
\hline Motors and Turbomachinery & $2,5,15,17$ \\
\hline Fluid Machinery & 3,9 \\
\hline
\end{tabular}

Note: Universities are given as numbers as are listed in Appendix B.

From the research, it is pretty evident that almost all selected universities cover most of the topics related to machines and mechanisms as shown in Table 4. The results are further shown in Fig. 1 in the form of 3-D chart where in the percentage of institutions offering such courses in each country are considered. Though there are thousands of universities in US alone, primarily the top ones were considered for the study according to ranking of engineering colleges in US universities ${ }^{[12]}$. Similar is the case with Canada, where too, the teaching standards are at par with the institutions in US.

Table 3. Universities in KSA offering courses covering topics of machines and mechanisms.

\begin{tabular}{|l|l|}
\hline Courses & Universities in KSA \\
\hline Combustion Engines & 2,5 \\
\hline Kinematics of Machines/Mechanisms & 1 \\
\hline Mechanisms (Analysis and Design) & $1,2,3,4,7$ \\
\hline Dynamics of Machines/Components & $1,2,3,4,5,7$ \\
\hline Robotics & 2,7 \\
\hline Manufacturing Processes/Machines & $1,3,4,5,6,7$ \\
\hline Nanomachines & 2 \\
\hline Static Machines & $2,6,7$ \\
\hline Motors and Turbomachinery & 2,7 \\
\hline
\end{tabular}

Note: Universities are given as numbers as are listed in Appendix C. 
Table 4. Percentages of universities in three countries (KSA, USA and Canada) covering topics of machines and mechanisms.

\begin{tabular}{|r|l|ccc|}
\hline \multirow{2}{*}{ No. } & \multicolumn{3}{|c|}{ Course Title } & \multicolumn{3}{|c|}{$\begin{array}{c}\text { Percentage of Universities offering } \\
\text { courses in machines and mechanisms }\end{array}$} \\
\cline { 3 - 5 } & & USA & CANADA & KSA \\
\hline $\mathbf{1}$ & Combustion Engines & 30.00 & 29.41 & 28.57 \\
$\mathbf{2}$ & Kinematics of Machines/Mechanisms & 45.00 & 47.06 & 14.29 \\
$\mathbf{3}$ & Mechanisms (Analysis and Design) & 40.00 & 82.35 & 71.43 \\
$\mathbf{4}$ & Dynamics of Machines/Components & 95.00 & 94.12 & 85.71 \\
$\mathbf{5}$ & Robotics & 30.00 & 47.06 & 28.57 \\
$\mathbf{6}$ & Manufacturing Processes/Machines & 50.00 & 47.06 & 85.71 \\
$\mathbf{7}$ & Nanomachines & 15.00 & 0.00 & 14.29 \\
$\mathbf{8}$ & Static Machines & 20.00 & 5.88 & 42.86 \\
$\mathbf{9}$ & Motors and Turbomachinery & 15.00 & 23.53 & 28.57 \\
$\mathbf{1 0}$ & Fluid Machinery & 0.00 & 11.76 & 0.00 \\
\hline
\end{tabular}

In the case of KSA (Kingdom of Saudi Arabia), it is noted that institutions are very limited here, as there are twenty public universities, in total. Out of these twenty, five or six are well-established with big campuses and a plethora of faculties and courses. The rest are still in the stage of infancy. The government has already sanctioned many more state of the art universities but most of them are still under construction. There are also a number of private universities and colleges which are also recently established.

The combustion engines course everywhere covers the different types of internal combustion engines, developments in direct ignition, rotary, pre-chamber, and stratified charge engines including the design of the combustion chamber. It is indeed an important subject for prospective mechanical engineers, although, unfortunately, not many universities are offering such a course, especially in US and Canada (both $30 \%$ ), as is evident from Fig. 1. In KSA, about $29 \%$ of universities offer such a course approximately, considering the sample of universities selected from each country. The other course which is rarely found is that of "Static Machines" which is covering nuts, bolts and fasteners and the various aspects of their designs.

One thing which is very prominent is the absence of courses on kinematics of machines/mechanisms in the universities of Saudi Arabia. It is present only in one university which is King Abdul Aziz University and is the first university in the Kingdom to have been accredited by ABET recently. Robotics is also an area that is widely covered in the 
engineering faculties across US and Canada. In some universities in US, e.g., Carnegie Mellon University, even Micro and Nano-robotics is covered, though peripherally. In contrast, in KSA, only one university, i.e., King Faisal University has presented a course related to Robotics in its Mechanical Engineering Undergraduate Program.

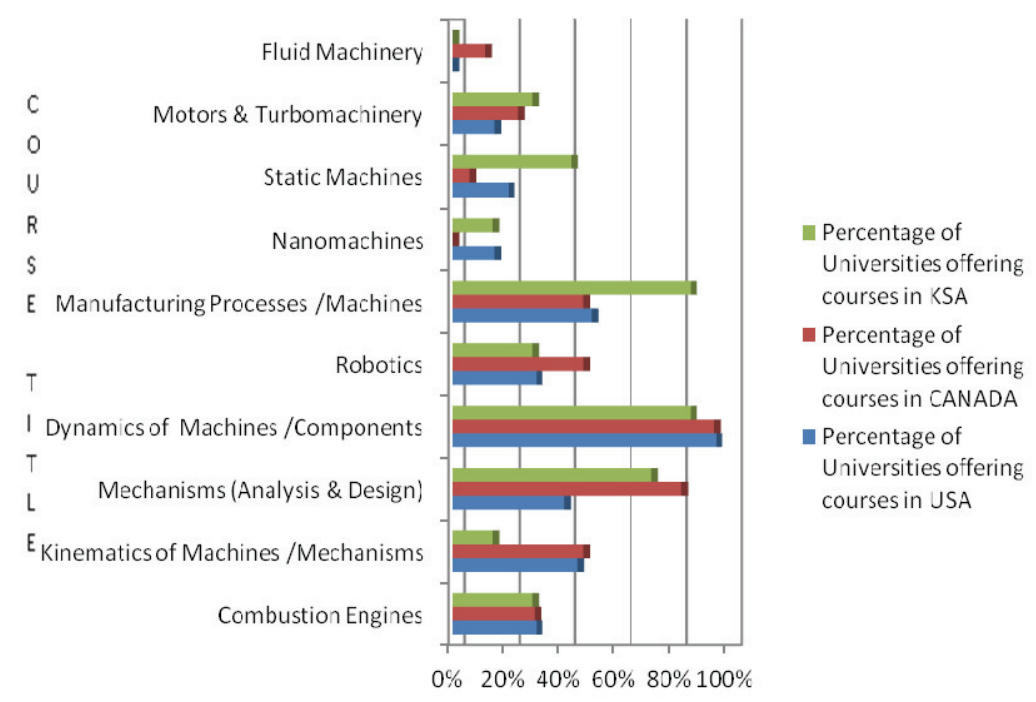

Fig. 1. Percentage of institutions offering mechanical engineering courses.

The progress of educational reforms has been a slow process, which have got very recently a shot in the arm with a large educational budget allocated by the Kingdom to build specialized universities. Barely three or four years back, KSA was having only three main universities having engineering and medicine courses, namely King Fahad University of Petroleum and Minerals (KFUPM), King Abdulaziz University (KAU) and King Saud University (KSU). All the three universities are still providing guidance for the upcoming universities in the Kingdom. The next section describes some emerging trends in the education industry concerning the areas related to machines and mechanisms.

It is to be emphasized that this study focuses on the existence of courses in selected universities rather than on quality or time spent in teaching and training in these courses. However, quality is implicitly included in the choice of these universities where primarily top ranking universities are selected from the USA and Canada while three of the Saudi Universities are ABET accredited and have some ranking among 
top universities meaning that they are basically at par with their counterparts in the USA and Canada ${ }^{[12]}$.

\section{Statistical Analysis}

Three classes of statistical hypotheses have been formulated prior to collecting the data for every course and then tested after data collection. The basic framework is that data from Saudi Arabia can be viewed as exhaustive (no sampling) since new universities are basically under construction and almost all of them are built and directed by the major universities included in the study. Thus, USA and Canada samples can be compared to KSA data. Let $p_{\mathrm{ij}}$ be the proportion of universities offering course $\mathrm{i}$ in country $\mathrm{j}$, where $i=1,2,3, \ldots, 10$ and $j=0,1$ or 2 denoting KSA, USA, and CANADA respectively. Then there are 30 formulated hypotheses as follows:

1- First ten hypotheses compare USA with KSA:

$$
\begin{array}{ll}
H_{0 \mathrm{i}}: p_{\mathrm{i} 1} \leq p_{\mathrm{i} 0}, & \mathrm{i}=1,2, \ldots, 10 \\
H_{1 \mathrm{i}}: p_{\mathrm{i} 1}>p_{\mathrm{i} 0}, & \mathrm{i}=1,2, \ldots, 10
\end{array}
$$

2- Second ten hypotheses compare Canada with KSA:

$$
\begin{array}{ll}
H_{0 \mathrm{i}}: p_{\mathrm{i} 2} \leq p_{\mathrm{i} 0}, & \mathrm{i}=1,2, \ldots, 10 \\
H_{1 \mathrm{i}}: p_{\mathrm{i} 2}>p_{\mathrm{i} 0}, & \mathrm{i}=1,2, \ldots, 10
\end{array}
$$

3- Third ten hypotheses compare USA with Canada:

$$
\begin{array}{ll}
H_{0 \mathrm{i}}: p_{\mathrm{i} 1}=p_{\mathrm{i} 2}, & \mathrm{i}=1,2, \ldots, 10 \\
H_{1 \mathrm{i}}: p_{\mathrm{i} 1} \neq p_{\mathrm{i} 2}, & \mathrm{i}=1,2, \ldots, 10
\end{array}
$$

The USA sample, made up of 20 universities, might be viewed as sampling with replacement because the population of universities in the USA is large. Thus, the binomial distribution might be used, and since the sample size is relatively large $(\geq 20)$ the normal distribution can also be used. Here, we use the binomial distribution. On the other hand, the Canadian sample has 17 universities which is less than 20. Thus, the binomial distribution is used with parameters $p_{\mathrm{i} 0}$ and $\left(1-p_{\mathrm{i} 0}\right)$ under the assumption that the null hypothesis is true. Here, in both cases the true proportion for any course can be assumed equal to $p_{\mathrm{i} 0}$ for every course $\mathrm{i}$. The level of significance, $\alpha$, is assumed to be 0.20 . However, when we 
deal with discrete distributions we might need to get a lower value of $\alpha$, say $\alpha_{0}$, and we reject the null hypothesis when the proportion is too large. The rejection region is determined as shown in the examples below. For comparisons between the USA and Canada we use Fisher's Exact Test ${ }^{[14,15]}$, with $n_{1}=20$ and $n_{2}=17$ for the USA and Canada, respectively.

In the first case, we use the course title 'static machines', i.e. $\mathrm{i}=8$, to compare USA with KSA using the binomial distribution as follows. Reject the null hypothesis if the sample proportion is too large. The level of significance is $\alpha_{0}=0.19136$. If the sample proportion corresponds to a cumulative probability lower than this $\alpha_{0}$, then reject the null hypothesis; otherwise the null hypothesis is not rejected. Here, the sample proportion is $0.2=(4 / 20)$ which corresponds to cumulative probability of 0.99169 which falls in the acceptance region, hence, the hypothesis cannot be rejected. This means that there is no evidence that supports the assertion that KSA is suffering from a deficiency in this course vis-à-vis USA.

The second example uses course title 'Kinematics of Machines/Mechanisms', $\mathrm{i}=2$, to compare Canada with KSA using the binomial distribution. Reject the null hypothesis if the sample proportion is too large. The level of significance is $\alpha_{0}=0.08360$. If the sample proportion corresponds to a cumulative probability lower than this $\alpha_{0}$, then reject the null hypothesis; otherwise the null hypothesis is not rejected. Here, the sample proportion is $0.4706=(8 / 17)$ which corresponds to cumulative probability of 0.00126 which falls in the rejection region, hence, the hypothesis is rejected. This means that there is evidence that supports the assertion that KSA is suffering from a deficiency in this course vis-à-vis Canada.

The last example uses the course title 'Mechanisms (Analysis and Design)', $\mathrm{i}=3$, to compare USA with Canada using Fisher's Exact Test, which uses the hypergeometric distribution, because the sample sizes are relatively small. This example will give the results for three alternative hypotheses; $H_{13}: p_{31}<p_{32}, H_{13}: p_{31}>p_{32}$, and $H_{13}: p_{31} \neq p_{32}$. The first two alternative hypotheses, included here just for illustrative purposes, are one-tail tests while the last one, which is our original hypothesis, is a two-tailed test. The corresponding contingency table for this case with pvalues is shown in Table 5 below: 
Table 5. Contingency table for Fisher's Exact Test of offering the course 'Mechanisms (Analysis and Design) with p-values for three alternative hypotheses.

\begin{tabular}{|l|c|c|c|}
\hline Offer Status & $\begin{array}{c}\text { USA } \\
\text { Universities }\end{array}$ & $\begin{array}{c}\text { Canada } \\
\text { Universities }\end{array}$ & Total \\
\hline $\begin{array}{l}\text { Yes, they offer } \\
\text { course 3 }\end{array}$ & 14 & 5 & 19 \\
\hline $\begin{array}{l}\text { No, they do not } \\
\text { offer course 3 }\end{array}$ & 6 & 12 & 18 \\
\hline Total & 20 & 17 & 37 \\
\hline
\end{tabular}

\begin{tabular}{|l|}
\hline \multicolumn{1}{|c|}{ p-values } \\
\hline Left $:$ p-value $=$ \\
0.997717 \\
Right : p-value $=$ \\
0.015855 \\
2-Tail : p-value $=$ \\
0.021709 \\
\hline
\end{tabular}

The implication of the two-tail p-value, in this example, is that if the level of significance is 0.05 , then the null hypothesis rejected. As with the first two examples, the decision to reject was made at a higher level of significance of around $20 \%$ which is normal for such studies. A summary of results of all these tests is shown in Table 6.

Table 6. Results of the tests of hypotheses for comparing the three countries.

\begin{tabular}{|l|l|l|l|l|l|l|}
\hline \multirow{2}{*}{$\begin{array}{c}\text { Course } \\
\text { No. }\end{array}$} & \multicolumn{2}{|c|}{ USA vs. KSA } & \multicolumn{2}{c|}{ Canada vs. KSA } & \multicolumn{2}{c|}{ USA vs. Canada } \\
\hline 1 & $\alpha_{\mathbf{0}}$ & \multicolumn{1}{|c|}{ Decision } & \multicolumn{1}{|c|}{$\alpha_{\mathbf{0}}$} & \multicolumn{1}{c|}{ Decision } & p-value & Decision \\
\hline 2 & 0.18612 & $\begin{array}{l}\text { Do not } \\
\text { reject }\end{array}$ & 0.18640 & Do not reject & 1 & Do not reject \\
\hline 3 & 0.14662 & Reject & 0.08360 & Reject & 1 & Do not reject \\
\hline 4 & 0.19841 & $\begin{array}{l}\text { Do not } \\
\text { reject }\end{array}$ & 0.09697 & Do not reject & 0.021709 & Reject \\
\hline 5 & 0.18612 & $\begin{array}{l}\text { Do not } \\
\text { reject }\end{array}$ & 0.08192 & Reject & 0.327674 & Do not reject \\
\hline 6 & 0.19841 & $\begin{array}{l}\text { Do not } \\
\text { reject }\end{array}$ & 0.07270 & Do not reject & 1 & Do not reject \\
\hline 7 & 0.14662 & $\begin{array}{l}\text { Do not } \\
\text { reject }\end{array}$ & 0.08360 & Do not reject & 0.234234 & Reject \\
\hline 8 & 0.19136 & $\begin{array}{l}\text { Do not } \\
\text { reject }\end{array}$ & 0.13923 & Do not reject & 0.347919 & Do not reject \\
\hline 9 & 0.18612 & $\begin{array}{l}\text { Do not } \\
\text { reject }\end{array}$ & 0.18640 & Do not reject & 0.679995 & Do not reject \\
\hline 10 & 0.00000 & $\begin{array}{l}\text { Do not } \\
\text { reject }\end{array}$ & 1.00000 & Reject & 0.204204 & Reject \\
\hline
\end{tabular}

\section{Some Emerging Trends}

Engineers, especially mechanical engineers, have been involved intimately with the development of machines; with mechanisms that use energy inputs to deliver desirable results. Indeed their preoccupation with 
machinery and with applying machinery to create wealth for their employers may be an intellectual barrier to the longer term goal of delivering a sustainable society. Future of the human race is standing on the corridors of altogether a different kind of technological development: nanotechnology. The world has already witnessed applications of nanotechnology in areas like manufacturing, automotive industry, aerospace engineering, biomedical engineering, building and construction industry, glass industry, diagnostics, textiles, consumer products, water engineering, drug delivery systems and nano computing.

Fast and extensive progress is being observed in many fields. For example, it has been reported that nanotechnology would have immense effect on the future of automotive industry and manufacturing processes in the Victorian automotive industry in Australia ${ }^{[13]}$ and with the passage of time, these developments are likely to have sustaining improvements in basic properties of future materials in terms of such features as the optical, structural, thermal, magnetic, catalytic electrical and properties of materials. Surprisingly, research is going on in such areas which humans could never have imagined. One of the examples of such kind of researches include inserting nano robots in the brain for making a person intelligent to different types of nano machines which when used in the industry, would revolutionize every bit of evolution. And how do we gain from such nano-robots in the future? That is best answered by a US inventor, involved in nano robots, when he said "We'll have intelligent nanobots go into our brains through the capillaries and interact directly with our biological neurons, which will make us smarter, remember things better and automatically go into full emergent virtual reality environments through the nervous system" ${ }^{[1]}$.

Thus, on the basis of the aforementioned facts, it is evident that together with information technology, biotechnology and cognitive science, nanotechnology is expected to radically alter the human conditions within a short span of time, probably not exceeding two to three decades or so.

\section{Conclusions and Recommendations}

Imparting education has never been easy, especially when it is in highly technical areas of engineering. This paper's scope is limited to the courses taught only at undergraduate level. However, further research 
may be undertaken wherein the researchers may include labs as well graduate courses. Though there were differences in contents of the courses taught in various universities in the areas of machines and mechanisms, still most of them are almost the same.

By the topics chosen for evaluation in the aforementioned areas, it was found that most of the universities in the US and Canada have included them in their mechanical engineering programs. As far as the topic Combustion Engines is concerned, it was found that closer to $30 \%$ of the universities in US are teaching it, while it is much lesser in Canada $(18 \%)$. While in KSA, it is almost the same as in US. The authors recommend that the combustion engines topic, being a prime area of mechanical engineering, should be given more importance and should appear more in the curricula of universities of the world, especially in Canada.

Similarly Kinematics of Machines/mechanisms should be covered more in the universities in KSA, where it is rarely found in the list of universities' courses (only 14\%). The courses related to Robotics are also not many even in the top notch universities in US (30\%), although it has always been, since its inception, an important area for engineers. Moreover, topics pertaining to fluid machinery should be included in the curricula of the universities in US and KSA which is not at all there now (as far as our samples indicate), particularly when it is there in two of the sampled universities in Canada.

It is also because the students are already learning the basic concepts of fluid mechanics, both as a core course and in special fluid mechanics labs, in most of the undergraduate programs. It will be of great help for the students to learn about the mechanical aspects of the fluid machines lab before doing the actual experiments. Similarly, Static Machines is one such course that needs urgent attention of the curricula designers of Canadian universities (only 6\%), because they essentially are part of any machine. Finally, Nano-Machines, which is today the hottest topic of engineering, has to find its place in curricula of the universities everywhere, because this is what is going to be the future of engineering per se. Unfortunately it is not available as a course in Canada, and in the US and KSA, it is available only in $15 \%$ and $14 \%$ of the sampled universities respectively. Emphasis should be given at imparting training in this course, so that at least students should know about the 
basics of future machines which are expected to replace each and every machine in every part of the world in the future. The nano-machine course is especially recommended for KSA, because the developing countries cannot lag behind the developed ones too much once globalization has opened all the borders for trade and commerce throughout the world.

\section{References}

[1] Briggs, H., "Machines to match man by 2029", (2008), source: http://news.bbc.co.uk/2/hi/7248875.stm, (retrieved: July 16, 2010).

[2] Kurita, Y., Ono, Y., Ikeda, A. and Ogasawara, T., "Human-sized anthropomorphic robot hand with detachable mechanism at the wrist," Mechanism and Machine Theory, 46(1): 5366 (2011).

[3] Palli, G. and Melchiorri, C., "Model and control of tendon-sheath transmission systems", Proceedings of the 2006 IEEE International Conference on Robotics and Automation, Orlando, Florida, 988-993(2006).

[4] Ikeda, A., Kurita, Y., Ueda, J., Matsumoto, Y. and Ogasawara, T., "Grip force control for an elastic finger using vision-based incipient slip feedback", Proceedings of 2004 IEEE/RSJ International Conference on Intelligent Robots and Systems, Sendai, Japan, 810-815 (2004).

[5] Engineering "Mechanical Engineering, (n.d.)". The American Heritage Dictionary of the English Language, Fourth Edition, (retrieved on July 20, 2010).

[6] Eckhardt, H.D., Kinematic Design of Machines and Mechanisms, McGraw-Hill (1998).

[7] http://www.histecon.kings.cam.ac.uk/research/machine_tools.htm, (retrieved on July 18, 2010).

[8] Feisel, L.D. and Rosa, A.J., "The Role of the Laboratory in Undergraduate Engineering Education", Journal of Engineering Education, 94(1): 121-130 (2005).

[9] U.S. National Archives, Records Group 404.1 Administrative History, www.archives.gov/research room/federal_records guide.

[10] http://www.ask.com/wiki/Educational_technology, (retrieved on July 19, 2010).

[11] Websites of all the universities given in Appendices A, B and C.

[12] http://www.topuniversities.com/, (retrieved on March 10, 2011).

[13] Hasan, S.W., "Maintenance management in nanotech-environment: the challenges ahead", International Journal of Nanomanufacturing, 4(1/2/3/4): 230-234, (2009).

[14] Agresti, A., "A Survey of Exact Inference for Contingency Tables", Statistical Science, 7(1): 131-153 (1992).

[15] Preacher, K.J. and Briggs, N.E., "Calculation for Fisher's Exact Test: An interactive calculation tool for Fisher's exact probability test for $2 \times 2$ tables [Computer software]. (2001, May), source: http://www.people.ku.edu/ preacher/fisher/fisher.htm, (retrieved on March 20, 2011). 


\section{Appendix A*}

\section{List of Universities in USA}

1. University of Alabama, $(351=, 32.61 ; 278,12.00)$

2. University of Arizona, $(160,52.35 ; 158,18.00)$

3. University of Arkansas, (551-600, 16.89)

4. Carnegie Mellon University, (34, 81.80; 12, 55.00)

5. Eastern Michigan University, (N/A; N/A)

6. University of Iowa, $(188,48.74 ; 295=, 12.00)$

7. University of Minnesota, $(96,66.58 ; 80,27.00)$

8. University of Mississippi, (N/A; N/A)

9. Massachusetts Institute of Technology (MIT), $(5,98.19 ; 1,100.00)$

10. University of Oklahoma, (401-450, 27.71)

11. University of Texas, $(67,71.24 ; 27,43.00)$

12. University of Virginia, $(130,58.30 ; 262=, 13.00)$

13. Washington State University, $(351,32.61 ; 244=, 14.00)$

14. University of Florida, (N/A; N/A)

15. Ohio State University, $(125,59.05 ; 157,18.00)$

16. Georgia Technical College, (N/A; N/A)

17. Harvard University, $(2,99.18 ; 22,45.00)$

18. University of Miami, $(235,42.97$; N/A)

19. Princeton University, $(10,96.03 ; 21,45.00)$

20. Stanford University, $(13,93.62 ; 2,83.00)$

\footnotetext{
${ }^{*}$ The first two numbers in brackets represent ranking and score of a university according to the QS ranking of top universities in the world, and the last two numbers represent ranking and score of the school of engineering in these universities. N/A = ranking not available.
} 


\section{Appendix B}

\section{List of Universities in Canada}

1. Royal Military College of Canada, (N/A; N/A)

2. University of Calgary, $(165,51.74 ; 151=, 19.00)$

3. Carleton University, (401-450, 25.62; N/A)

4. Concordia University, (401-450, 25.56; N/A)

5. Dalhousie University, (212, 46.40; N/A)

6. University of McGill, (19, 89.25; 29, 43.00)

7. University of New Brunswick, (216, 45.60; N/A)

8. Memorial University of Newfoundland, (N/A; N/A)

9. University of Ottawa, $(231,43.54 ; 231=, 14.00)$

10. University of Saskatchewan, (ranked in the top 20 schools in North America)

11. Schulich College, (N/A; N/A)

12. University of Toronto, $(29,84.29 ; 14,54.00)$

13. University of British Columbia, $(44,77.41 ; 30,42.00)$

14. University of Victoria, $(241,42.64 ; \mathrm{N} / \mathrm{A})$

15 . University of Waterloo, $(145,54.73 ; 39=, 38)$

16. University of Western Ontario, $(164,51.83 ; \mathrm{N} / \mathrm{A})$

17. University of Windsor, (N/A; N/A)

\section{Appendix C}

\section{List of Universities in Saudi Arabia}

1. King Abdul Aziz University, (401-450, 26.10; N/A)

2. King Faisal University, (N/A; N/A)

3. King Fahad University of Petroleum and Minerals, $(255,41.51 ; 258=, 13.00)$

4. King Saud University, (221, 44.89; N/A)

5. Umm Al-Qura University, (501-550, 19.29; N/A)

6. Yanbu College, (N/A; N/A)

7. Al-Qassim University, (N/A; N/A) 


\section{التعليم والتدريب في مجال الآلات والآليات (دراسة مقارنة)}

\section{إبراهيم عبدالعزيز الضراب، و سيد وصي الحسن}

قسم الهندسة الصناعية، كلية الهندسة، جامعة الدلك عبدالعزيز،

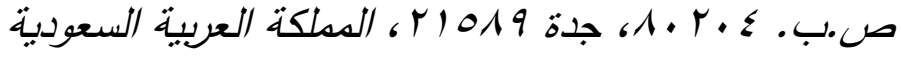

wasiulhasan@yahoo.com \&iadarab@gmail.com

الستخلص. كانت الآلات والآليات قد استعملت على الدوام كأدوات

لتحسين حياة الإنسـان وطريقة معيشته، كما بـأ الناس استعمالها

بتحويل الهوارد الطبيعيـة إلى أنثكال وصـور متعددة مـن الأدوات القديمة التي صنعها الإنسان. ولقد كان الحال مشابها في أحد أهم الفال

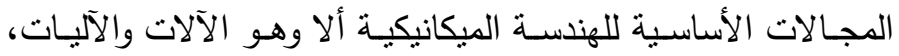

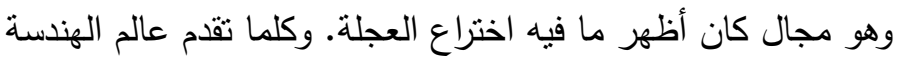

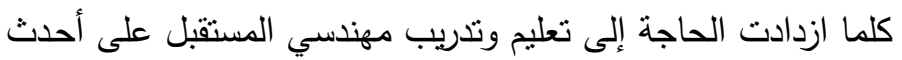

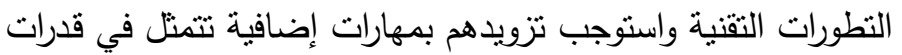

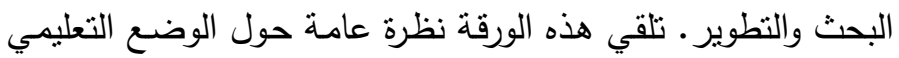

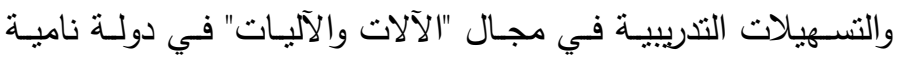
كالمملكة العربية السعودية. أظهرت الدراسة أن المملكة تركز حاليا

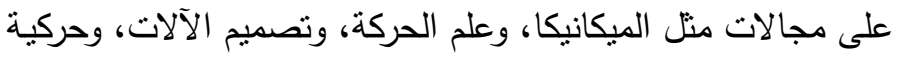
الآلات، ونظرية الآلات التي تدرس في الجامعات باتلات بعموم المملكة.

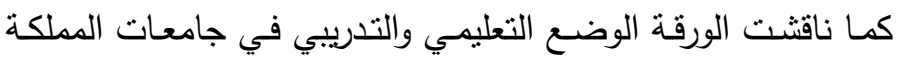

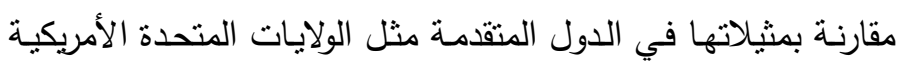

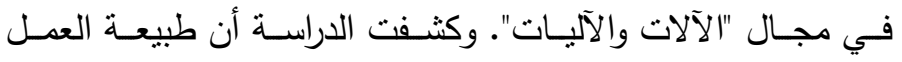

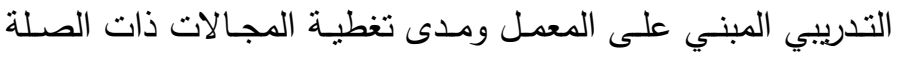

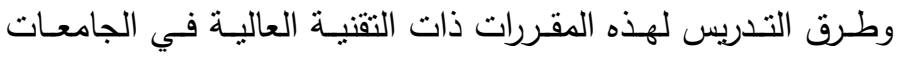


السعودية تحتاج إلى مزيد من التحسين لتكون مضارعة لمثيلاتها في

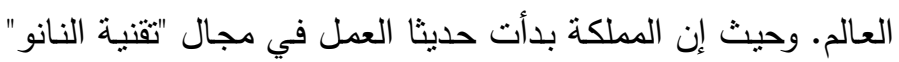
فقد تم إلقاء الضوء على تأثير ذلك على تصميم وتطوير البرامج المستقبلية المتعلقة بالآلات والآليات. وتخلص الورقة إلى توصيات

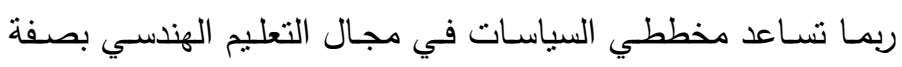
عامـة والآلات والآليات بصفة خاصـة لمسـقتبل نـاجح للدول الناميـة لمواكبة أحدث الابتكارات . ل عالات والات كلمات مفتاحية: الهندسة الميكانيكية، التعليم الجامعي، المناهج

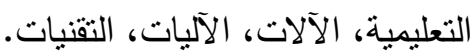

